\title{
Analysing Online Teaching and Learning Systems Using MEAD
}

\author{
Shona Leitch and Matthew J. Warren \\ School of Information Systems, Faculty of Business and Law, \\ Deakin University, Burwood, Victoria, Australia
}

\author{
shona@deakin.edu.au; matthew.warren@deakin.edu.au
}

\begin{abstract}
The review of literature pertaining to systems analysis and design and the design of systems for online teaching and learning has identified some "gaps" and has shown the need for a more specialised and specific method for the design of such systems. This paper presents research that was conducted to collect information to assist in the filling of the gaps of the systems analysis and design knowledge within Australia and also presents a method for the development of online teaching and learning systems. Currently design is done in an ad-hoc fashion with little formal input from the student users; this research aims to rectify this. The paper puts forwards an educational design approach based upon Soft Systems Methodology (SSM). The outcome of the research is a practical method - the Method for Educational Analysis and Design (MEAD).
\end{abstract}

Keywords: Soft Systems Methodology (SSM), Method for Educational Analysis and Design (MEAD), Online learning.

\section{Introduction}

The online learning phenomenon has become more widespread in recent years with many learning institutions adapting ways of incorporating modern technology into learning skills and objectives to facilitate students learning.

Online Learning is becoming an ever-increasing way of facilitating education to students who are unable to attend a traditional on-campus university as well as supporting on-campus teaching. The most common systems used by educational establishments are asynchronous learning systems (online learning systems) (Lewis, Snow, Farris, \& Levin, 1999).

Online learning does not just denote how learning is conducted but is "an educational philosophy for designing interactive, responsive and valid information and learning opportunities to be delivered to learners at a time, place and in appropriate forms convenient to the learners" (Boettcher, 2004) or, even more simplistically put, learning conducted using the web and a personal computer (Petrova, 2004).

Material published as part of this publication, either on-line or in print, is copyrighted by the Informing Science Institute. Permission to make digital or paper copy of part or all of these works for personal or classroom use is granted without fee provided that the copies are not made or distributed for profit or commercial advantage AND that copies 1) bear this notice in full and 2) give the full citation on the first page. It is permissible to abstract these works so long as credit is given. To copy in all other cases or to republish or to post on a server or to redistribute to lists requires specific permission and payment of a fee. Contact Publisher@InformingScience.org to request redistribution permission.
Clark (1991) suggested that teaching and studying at a distance can be as effective as traditional instruction provided: (a) the methods and technologies used are appropriate to the instructional tasks, (b) there is student-to-student interaction, and (c) there is timely teacherto-student feedback. 
After a review of relevant educational literature it was found that there is no one specific method for the analysis of online teaching and learning systems. Also often the strategies presented are not student driven, hence the requirement of an alternate student focused method.

\section{Background to SSM}

SSM (Soft Systems Methodology) is a method that has been used by many and applied in different aspects of business and beyond (Checkland, 1981, 1988, 2000). It is often not referred to as a methodology but a problem solving tool, which makes it suitable for a variety of situations.

Checkland's SSM focuses on organisational problems by considering the organisation as a whole, not just looking at one particular problem and not attempting to make an early decision on a solution to a problem (Checkland, 1998; Checkland \& Scholes, 2000). SSM works through a number of stages that are illustrated in Figure 1. There are a total of seven stages in the standard SSM methodology.

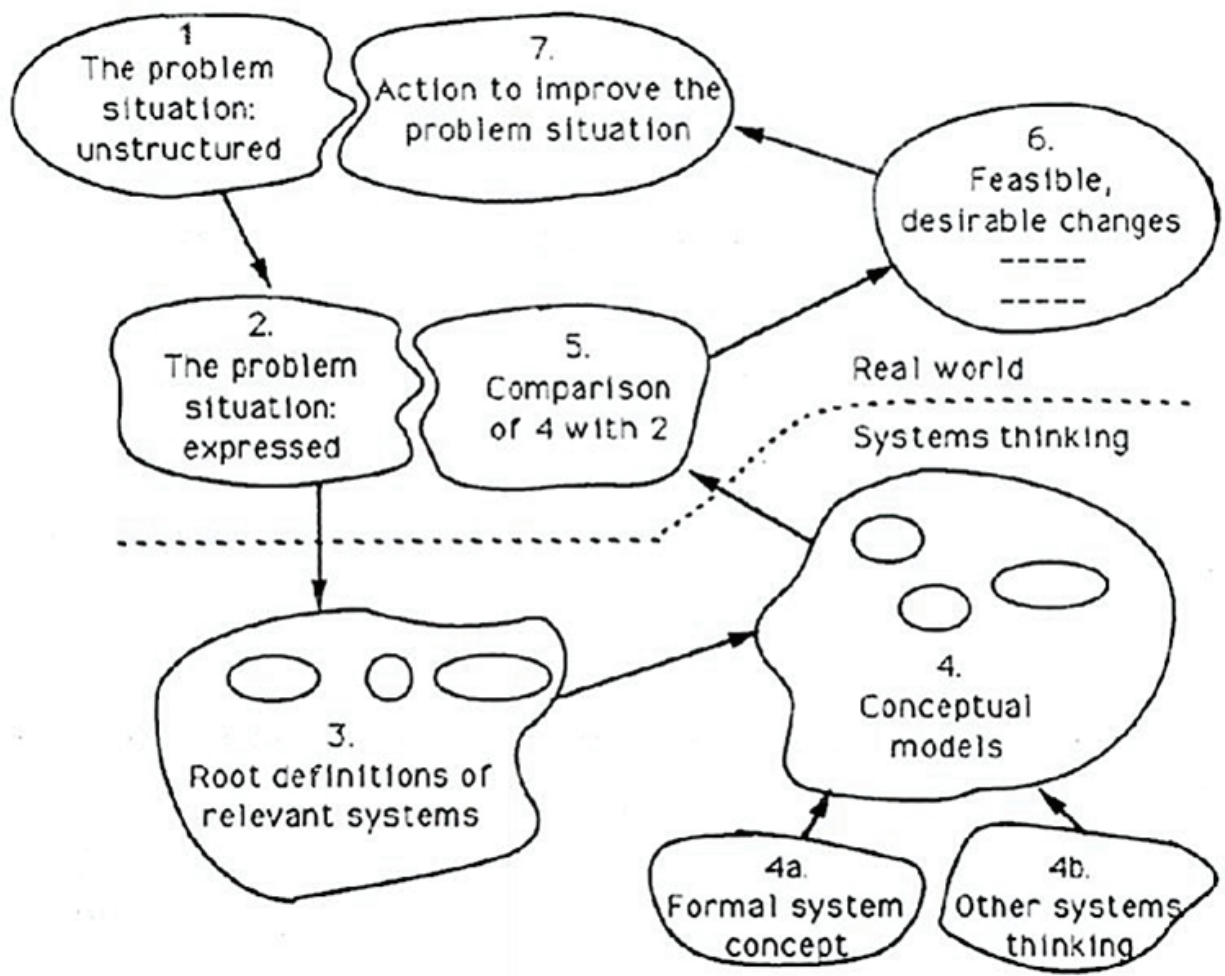

Figure 1: Stages of Soft Systems Methodology (from the original figure created by Checkland, 1981)

Gencoglu, Altmann, Smith, \& Mackay (2002) applied SSM to the study of supply chain management (SCM) on the premise that SCM is affected by cultural, political, and social issues and that SSM would be an effective tool to deal with these "soft" problems. The research centred on workshops where the participants in the SCM made use of the techniques of SSM (rich pictures, conceptual models, etc). It was concluded that the use of SSM gave the participants a greater understanding of the problem situation, and they could identify issues and conflicts more effectively. This research highlights the effectiveness of SSM to be used in many situations and be useful in situations without easy solutions. 
SSM was used by Patel (1995) to analyse the teaching and learning process in a higher education institution. The standard stages of SSM were followed and the "area of concern" was wide ranging. The results produced fifteen recommendations, some of which were previously unrecognised by the lecturers.

\section{Development of MEAD}

It was decided to use SSM as a basis for the method for the analysis and design of online teaching and learning systems for a number of reasons:

- SSM is a well known, internationally used methodology and has been used in a variety of settings since its development in the early 1980s;

- SSM allows for flexibility in its application to suit the discipline and area under investigation;

- SSM encourages ownership of the problem situation by involving stakeholders in the process;

- The organisational aspects of the situation can be addressed. This may be especially important in regards to online teaching and learning systems, as it is not an isolated system, but governed by policies, procedures and structure of its environment;

- The use of rich pictures will be a communication tool with students and will present the issues in a non-threatening and easy understandable fashion. They will also aid in the participation aspect of the method.

The user participation aspect of SSM was one of the most important features when deciding to use SSM as the basis of the method. It allows the inclusion of the different perceptions and opinions of stakeholders within the problem situation. As this method is a student driven approach it is the opinions and values of that group that will formulate the analysis and design, not the perception of the designers or teaching staff.

Initially a conceptual model was created identifying from the literature the most important features that should be included in the method. These were separated into three main categories:

- Concept and Content

- The theories and methods to be used to undertake the analysis and design;

- Participation

- The different types and level of participation that will take place;

- Development and Structure

○ How the content and participation will be included in the development process. These features were then incorporated into the framework of SSM to produce a new method MEAD.

MEAD consists of seven stages as shown in Figure 2. As well as the seven main stages of this method there is participation that takes place at numerous stages of the method.

- Stage Two: In stage two a participant survey and focus group session are both used. The survey provides the initial data for stage two and the focus group session provides validation of SSM conceptual, real world models and updating.

- Stage Five: In stage five the real world models that are developed are discussed (a walkthrough scenario) with an online designer expert to assess their validity.

- Stage Seven: The completed design and implemented changes are presented to a focus group of online teaching and learning system users for their assessment and comments. 


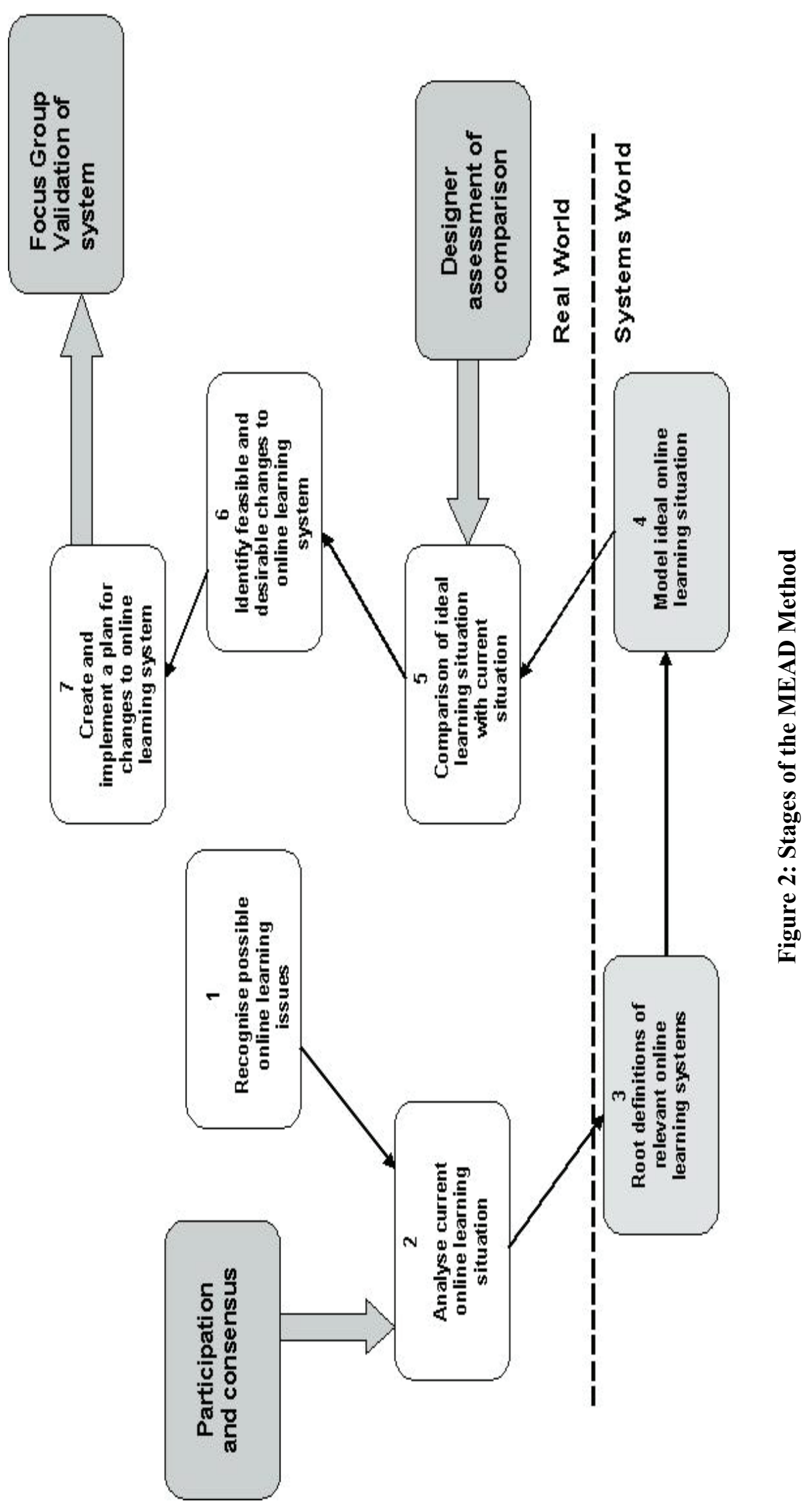




\section{The Stages and Implementation of MEAD}

The method was implemented in Deakin University, a tertiary institution located in Victoria, Australia. Deakin University is one of Australia's largest universities (Deakin University, 2007), with five campuses located in Melbourne, Geelong, and Warrnambool. It was established in 1974 with one campus located in Geelong. Deakin University was one of the first Australian universities to introduce off-campus learning, first through traditional paper methods and then through Internet technologies. Since 2004, all new undergraduate students have been required to undertake at least one wholly online unit as a part of their degree (Deakin University, 2007), and most units have an online teaching and learning presence. Deakin University currently uses software called Deakin Studies Online (DSO) a part of the WebCT brand of software. This software is used in almost every unit at Deakin University with a "required" amount of information (unit guide) to be provided to students (Faculty of Business and Law, 2007a, 2007b) however most units have a much wider DSO presence, supplying various learning materials, lectures, tutorials, discussions etc.

The application involved participation from an online teaching and learning expert as well as users of online teaching and learning systems (in the form of a survey and two focus group sessions).

The following describes the implementation of the stages.

\section{Stage 1 - Recognise Possible Online Learning Issues and Stage 2 - Analyse Current Online Learning Issues}

Stage 1 requires the recognition that there is an issue with the current online teaching and learning system and, therefore, some action is required to improve the situation. Usually there is at least one person that recognises the possible problem situation and takes action to improve it. In the case of the online teaching and learning system, this is likely to be an academic staff member who has been informed by students as to problems or limitations of the current system, or has noted through their own teaching problems with the current system in terms of its design or lack of content and functionality.

In this case of this practical application, informal student comments and the staff member's awareness of issues and limitations were the initiation for an investigation into the situation.

The work completed in stage 1 of the method was a combined effort guided by the designer with a large amount of input and consensus by the focus group participants.

Stage 2 focuses upon analysing the current online learning issues; this stage has a key focus of data elicitation. Data was collected through a survey, gauging students' opinions and attitudes to numerous areas of teaching and learning online at Deakin University. The responses were collated and used to form a consensus opinion as to their attitudes towards these elements. These opinions were then used to create the initial rich picture and problem themes.

The stage also involved the use of a focus group. The first focus group was conducted with a group of students from Deakin University, Australia, who indicated in the returned questionnaire that they were willing to be interviewed. From this list a sample of students were selected.

The first was a group discussion of students' attitudes, experiences, and opinions of Online Teaching and Learning systems (specifically DSO).

Discussion on the positive and negative aspects of online learning systems layout, content, and design took place.

The final major part of the focus group session involved the presentation of a Rich Picture (Checkland, 1998) and the associated Problem themes and were offered up for discussion. Stu- 
dents were asked to comment on each theme and identify any other problems that had not been identified.

The outcome of the first focus group session was to be able to validate and update the rich picture and problem themes that were developed from the survey responses.

\section{Stage 3 - Root Definitions of Relevant Online Learning Systems and Stage 4 - Model Ideal Online Learning Situation}

These outcomes allowed the researchers to proceed to stage 3 of the method and formulate the root definitions formulated from the earlier stages. Stage 4 focuses upon encapsulating the fluid information into a conceptual model that reflects the ideal online teaching and learning situation.

\section{Stage 5 - Comparison of Ideal Learning Situation with Current Situation}

When reaching stage 5 of the method (comparing the ideal situation with the current situation) an e-learning expert from Deakin University was approached and an interview was conducted, during which the researchers' models were discussed and feedback was given by the expert. This feedback was then included in the models before the comparison was conducted.

\section{Stage 6 - Identify Feasible and Desirable Changes to the Online Learning System}

From the research that has been conducted in the application of this method (from focus group sessions, questionnaire feedback, and analysis using the method) there are a number of changes to online teaching and learning system at Deakin University that have been discussed and proposed by the researcher, the participants, and the e-learning expert. These include:

- Implement a social networking and interaction aspect to online teaching and learning;

- Provide more useful information resources;

- Provide varied resources for students that include both audio, visual, and interactive mediums;

- Larger Internet download limit for student to access materials suggested by staff on DSO for students to access;

- Wholly online units to be removed from the curriculum and online teaching and learning to be used as a supplemental resource to traditional face-to-face teaching;

- Online questions posed by students to be replied to by a staff member within twenty-four hours;

- Lecture theatres to be fitted with adequate power outlets for students to be able to use laptops to take notes during classes (outside the realm of online teaching and learning system design);

- Users (students) of online teaching and learning systems should have input into the design of said system;

Within this stage another area to be assessed was the limitations of Technology involved. The limitations of the online teaching and learning software (DSO) used by Deakin University had to be addressed. WebCT the development company that produced DSO provides a generic standardised package, which is then adapted for use at individual institutions. Even with Deakin Univer- 
sity, different templates and styles are used within different Faculties. Some of the limitations faced when developing the DSO example site included:

- Limited selection of integrated communication tools

- No standard method for social interaction

- Database style of DSO (would be difficult to alter)

- Overall style of DSO site

These limitations along with the scope of this study and changes that would need to be implemented at a University level meant that a number of the desirable changes were not feasible.

The following section outlines those changes which are considered feasible. From the desirable changes and applying the limitations explained, the feasible changes were identified. They are:

- Implement a social networking and interaction aspect to online teaching and learning;

- Provide more useful information resources;

- Provide varied resources for students that include both audio, visual, and interactive mediums;

These changes were used as the basis for the creation of example DSO site to be presented to and validated by the second focus group participants.

\section{Stage 7 - Create and Implement a Plan for Changes to Online Teaching System}

The feasible changes that were identified through the SSM analysis were then applied to the specific online teaching and learning system that is used at Deakin University. Along with these feasible changes the specific opinions of the focus group participants (and the survey participants) were also applied to the design and the content inclusions.

A second focus group session was conducted; the participants were presented with the example online teaching and learning system that was produced from the "feasible and desirable changes" that were identified in stage six of the method. This part was presented in the style of a walkthrough, showing the participants the different elements and features that had been included. This included content ideas as well as some different layouts. A detailed discussion regarding the changes that had been made was undertaken.

The results of focus group two and the walkthrough of the example DSO site were very positive. Students reacted well to the change in design and layout and were particularly enthusiastic about the changes in content, especially the use of new software (interactive revision) and the unique and varied information that was supplied to them.

\section{Conclusion}

The research has provided a new practical method called MEAD developed for the development of on-line teaching and learning systems based upon user (students) participational approach. The MEAD method has adapted the traditional SSM methodology to be more applicable within the area of online teaching and learning system design. This adaptation included adding participation in the form of a survey, focus groups, and a walkthrough with an online teaching and learning expert to create a new method.

It contains a high level of user participation in numerous stages of the method allowing online teaching and learning systems to be responsive to the student users. MEAD has filled a gap in the 
knowledge in the area of development methods for the analysis and design of online teaching and learning systems by producing a formal method that is student-user focused. This online teaching and learning method has been developed as an alternate way of developing online learning systems. The approach allows for high levels of user involvement at specific stages of the method. This is to endeavour to improve the planning and analysis of online learning systems and try to achieve a system that works for the user.

The application of this method took place in a tertiary institution (Deakin University) in Australia and the participants were all current students at this university. The outcome of the application of this method has been (in the participants' opinion) a more user friendly, acceptable format for online teaching with an improved content and more interesting through the use of different mediums. Future research could be focused upon implementing the MEAD method in a number of different countries to determine cultural differences.

\section{References}

Boettcher, J. (2004). Definitions and models. University Computing and Communication Services: Sacramento. Retrieved 23/4/2007 from http:/www.csus.edu/uccs/training/online/overview/define.htm.

Checkland, P. (1981). Systems thinking, systems practice. Chichester: Wiley.

Checkland, P. (1988). Soft systems methodology: An overview. Journal of Applied Systems Analysis, 15, 27-30. University of Lancaster, Department of Systems.

Checkland, P. (1998). Soft systems methodology in action. Wiley, ISBN 0471986054.

Checkland, P. (2000). Soft systems methodology: A thirty year retrospective. Systems Research and Behavioral Science, 17(S1), S11-S58.

Checkland, P., \& Scholes, J. (2000). Soft systems methodology in action. Chichester: John Wiley and Sons.

Clark, R. E. (1991). Reconsidering research on learning from media. Review of Educational Research, 53, 445-459.

Deakin University. (2007). About Deakin. Retrieved 1/5/2007 from http://www.deakin.edu.au/about/history.php

Faculty of Business and Law (Deakin University). (2007a). Faculty of Business and Law staff manual (Deakin University). Retrieved 4/4/08 from http://www.deakin.edu.au/buslaw/staff-only/index.php

Faculty of Business and Law (Deakin University). (2007b). Onlineness checklist. Retrieved 1/3/08 from http://www.deakin.edu.au/buslaw/staff-only/teach-learn/docs/onlineness-checklist.doc

Gencoglu, G., Altmann, G., Smith, R., \& Mackay, D. (2002). Using soft systems methodology to address supply chain management problems. Australian Journal of Information Systems, 9(2), 49-56.

Lewis, L., Snow, K., Farris, E., \& Levin, D., (1999). Distance education as post secondary education institutions, 1997-98. National Center For Education Statistics 2000-013. Retreived 1/11/07 from http://ship.nime.ac.jp/ saga/project/usdised.pdf

Patel, N. V. (1995). Application of soft systems methodology to the real world process of teaching and learning. International Journal of Educational Management, 9(1), 13-23.

Petrova, K. (2004). Mobile learning usage using SMS: A mobile business application. Proceedings of the 17th National Advisory Committee on Computing Qualifications, NACCQ 2004. Retrieved 4/2/2007 from http://www.naccq.co.nz/conference05/proceedings_04/petrova_mlearn.pdf 


\section{Biographies}

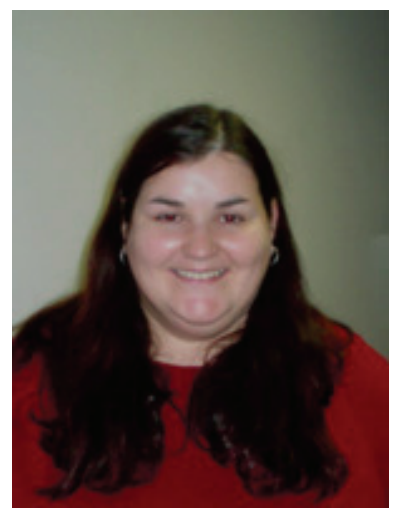

Shona Leitch is a Lecturer in the School of Information Systems, Deakin University. Shona is originally from Scotland, emigrating to Australia in 1998. She obtained her BSc (Hons) in 1997 from the University of Plymouth in Psychology/Computing. Her main teaching and research focus is the area of Systems Analysis and Design. She has taught various units on this subject. She is also recently submitted a $\mathrm{PhD}$ entitled "A Systems Analysis and Design Strategy for Online Teaching and Learning Systems". Shona has also completed a Grad Cert of Higher Education. She has published over 25 papers, in books, journals and conferences, in the areas of systems analysis, online teaching and information security.

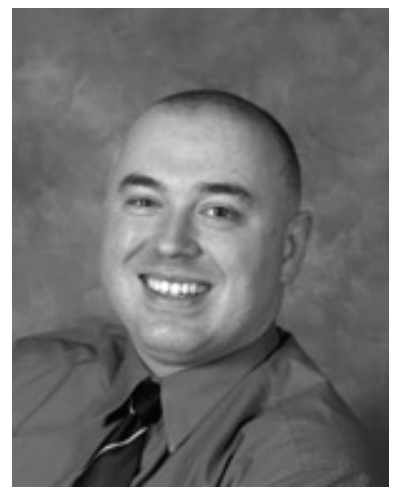

Prof. Matthew Warren is the Head of School and a Professor in the School of Information System, Deakin University, Australia. He has a $\mathrm{PhD}$ in Information Security Management from Plymouth University, UK. Professor Warren has received over three million dollars of research funding awards from national/international funding bodies.

Professor Warren has gained international recognition for his scholarly work in the areas of Information Security, Risk Analysis, eBusiness, Information Warfare, Online Teaching and Learning Systems and Critical Infrastructure Protection.

Professor Warren is the former Chair of IFIP TC 11 Working Group 11.1 - Security Management and a former Director of the Australian Institute of Computer Ethics. Professor Warren has taught within Australia, Finland, Hong Kong and the UK. 